\title{
23. Studies on Tropolone Derivatives. III. On Methyl Ethers of Tropolone and Its Halogen Derivatives.
}

By Tetsuo Nozoe, Shûichi Seto, Toshiaki Ikemi, and Takuzô AraI.

Chemical Institute, Faculty of Science, Tôhoku University.

(Comm. by R. Majima, M. J. A., Feb. 12, 1951.)

Nozoe et al. ${ }^{1 a}$ found that the ether (II) of hinokitiol (I), i. e. $\mathrm{m}$-isopropyltropolone, was more similar to the esters of carboxylic acids or enolic ethers than the ethers of aliphatic alcohols and of aromatic phenols, in point of the ease of hydrolysis by acids or alkalies. They assumed that the ease of the hydrolysis of (II) might be caused by the strong inclination of returning to the more stable original state (I), due to the increase in basicity and decrease of stability in (II) resulting from the restriction of resonance by fixation of acidic hydrogen atom which is responsible for the hydrogen bond resonance in (I) ${ }^{2}$. It was supposed that in contrast with the case of (I), the easy reduction ${ }^{1 a)}$ of (II) to saturated cyclic diol by metallic sodium and alcohol was also due to the decreased stability of (II) compared to (I) and especially its salt or anionoid form. Dewar") assumed for C-ring in colchicine a structure (IIIa) corresponding to methyl ether of tropolone and, moreover, he proposed a resonance with the ionic form (IIIb) to explain its unusually high solubility in water.

As to the ethers of tropoloid compounds, methyl ethers of purpurogallin and stipitatic acid have been reported ${ }^{+1}$, but their properties have not been described in detail.

The present paper describes the properties of methyl ethers of tropolone (IV), the mother substance of this series, and its bromo derivatives, considering the characteristic structure and properties of tropoloid compounds, as well as the unique biological action of colchicine.

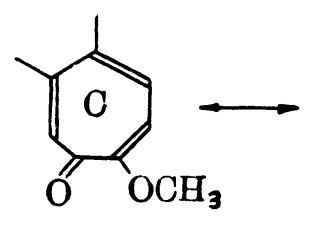

(IIIa)

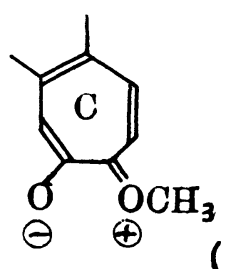

(IIIb)

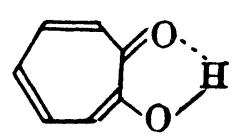

(IV)

Nozoe, et al. ${ }^{1 \mathrm{~b})}$ previously obtained methyl, ethyl and isopropyl ethers of (I) by the action of alkyl halides with $\mathrm{Na}$ and $\mathrm{Ag}$ salt of (I), but in the case of (IV), due to the very high water-solubility 
of the reaction product, this method was found disadvantageous. However, the reaction of (IV) with diazomethane in ether easily gave its methyl ether in crystalline form (Va), m.p. $41^{\circ}, \quad B y$ drying in vacuum desiccator, or by distillation, it changed to an oily form $(\mathrm{Vb})$, which on standing in the air, returned to crystals, rapidly absorbing $1 / 2$ mole of water, and subsequently absorbed more water slowly (Fig. 1).

This fact and the analytical values of (Va) showed that methyl ether of tropolone is stabilized especially by taking $1 / 2$ mole of water of crystallization. ( $\mathrm{Va}$ ) and $(\mathrm{Vb})$ are soluble in water in any proportions are stable on boiling with water and give no coloration with $\mathrm{FeCl}_{\text {. }}$. (Va) however, is readily hydrolyzed to (IV), by boiling with dil. acid or dil. alkali (Table I).

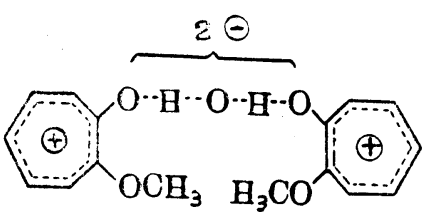

( Va)

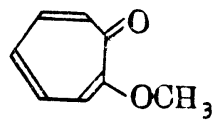

(Vo)

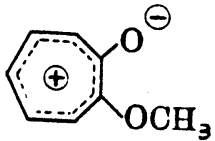

(Vc)

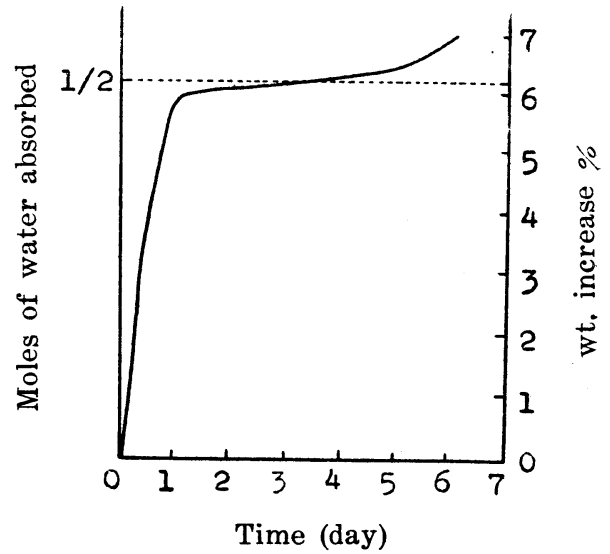

Fig. 1. Increase in the weight of $(\mathrm{Vb})$ on standing in the air.

Table I. Hydrolysis of Tropolone Methyl Ether at $100^{\circ} \mathrm{C} . \%$.

\begin{tabular}{|c|c|c|c|}
\hline Conc. of Sample (M) & 0.0621 & 0.0296 & 0.0293 \\
\hline Time (min.) & $\mathrm{H}_{2} 0$ & $\begin{array}{c}\mathrm{HCl} \\
\mathrm{N} / 20 \times 1.029\end{array}$ & $\begin{array}{c}\mathrm{NaOH} \\
\mathrm{N} / 20 \times 0.892\end{array}$ \\
\hline 10 & 0 & 3.75 & 51.00 \\
\hline 30 & 0 & 17.75 & 89.06 \\
\hline 60 & 0 & - & 96.29 \\
\hline 80 & 0 & 31.14 & \\
\hline 15$\}$ & 0 & 45.04 & \\
\hline
\end{tabular}

Hinokitiol and tropolone were previously postulated by $\mathrm{Nozoe}^{2)}$ to have three types (A, B and C) of resonance structures with a large number of non-ionic and ionic forms, to explain their remar- 
kable characters. From the results of measurements of their dipole moments and magnetic susceptibilities carried out by his co-workers, Kuko, Hazato, et al., it was established that the structure of this system in normal state can be well explained mainly by the resonance of type $\mathrm{B}^{\text {i) }}$. Further, type $\mathrm{C}$ can be assumed as the activated structure of fundamental type $A$ in the case of reaction with electrophilic reagents. It is suggested that, in methyl ether of tropolone, due to the substitution of methyl group for acidic hydrogen atom of (IV) which is responsible for the hydrogen bond resonance in tropoloid system, contribution of type $\mathrm{A}(\mathrm{Vb})$ in the normal state becomes smaller, while both the basicity of dipolar type (Vc) and the affinity for water are increased. The fact that (Vb) stabilizes by absorbing $1 / 2$ mole of water may be explained by a resonance structure such as (Va). These points will probably be ascertained by the measurements of dipole moments and other physical properties.

The hydrolysis by acid and alkali may be illustrated by the following scheme.

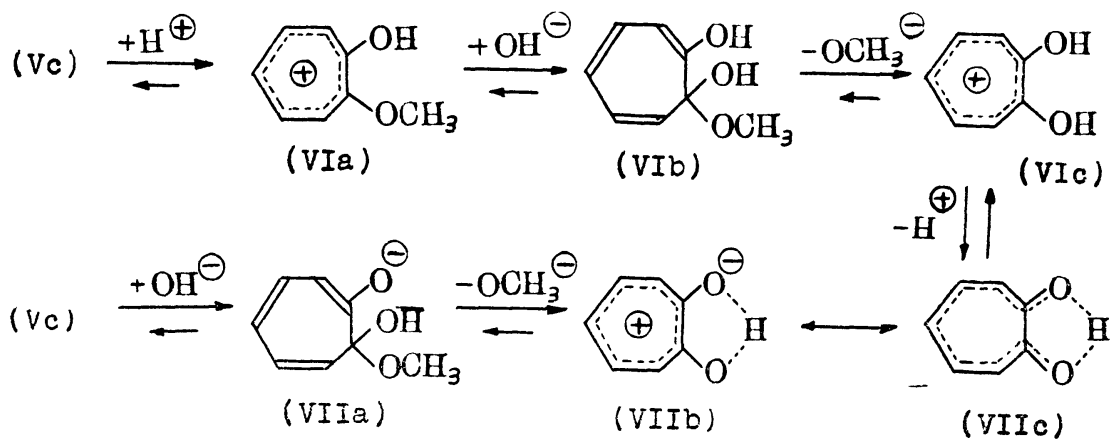

The fact that (VIa) can stabilize itself more easily than (VIIa) is enough to show that this ether is more stable against acid than to alkali.

As in the case of (II), b. p. of (Vb) is higher than that of (IV), contrary to the case of normal ethers, showing the larger contribution of ionic forms in the ether than in tropolone itself.

The coupling of $(\mathrm{Vb})$ with diazonium salt in water does not occur even when alkali is added to $\mathrm{pH} 8$. Bromination of $(\mathrm{Vb})$ in water gives precipitation of tribromotropolone, m. p. 125-126 ${ }^{\circ}$. (Vb) also does not react with phenylhydrazine, semicarbazide and aniline.

Nozoe, Kitahara, et a1.(5) reported that o-bromotropolone, having an asymmetric structure, gave two kinds of isomeric methyl ethers (m. p. $91.5^{\circ}$ and $50^{\circ}$ ). In the present work, three kinds of bromo derivatives, --i. e. p-monobromotropolone (VIII), o, $o^{\prime}$-dibromo- 
tropolone (IX) and o, p, o'-tribromotropolone (X) -- each gave only one kind of methyl ether ((VIIIa), m. p. 135-136 ${ }^{\circ}$; (IXa), 132$132.5^{\circ}$; $\left.(\mathrm{Xa}), 110-111^{\circ}\right)$, as was expected from their symmetric structures.

These ethers have higher solubility in water than the original. substances and are readily hydrolyzed by acid or alkali.

Their infrared and ultraviolet absorption spectra, magnetic susceptibility and other physical properties and their effect on Yoshida sarcoma ${ }^{7}$ as well as on mitotic cells of animals and plants will be reported in the future.

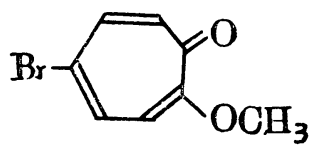

(VIIIa)

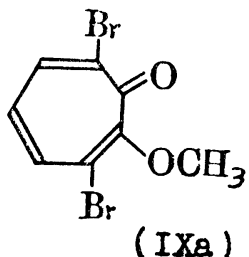

( IXa)

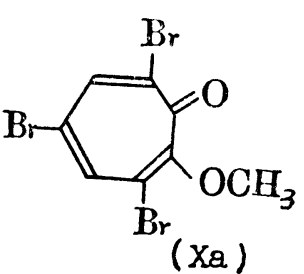

(Xa)

\section{Experimental ${ }^{*}$.}

Methyl Ether (Vc) of Tropolone (IV):-Addition of ether soln. of diazomethane to (IV) in ether precipitated pale yellow needles (Vc), m. p. $41^{\circ}$, with evolution of $\mathrm{N}_{2}$. The crystals (Vc) contain $1 / 2$ mole crystal water. On distilling at $128^{\circ} / 5 \mathrm{~mm}$., or drying in vacuum desiccator, it lost its cryştal water and turned into an oil. (Tropolone, b. p. $85^{\circ} / 5 \mathrm{~mm}$.) (Vc) : Anal. Calcd. for $\left(\mathrm{C}_{s} \mathrm{H}_{8} \mathrm{O}_{2}\right)_{2} \mathrm{H}_{2} \mathrm{O}$; C, 66.19; H, 6.25. Found: C, 65.89; H, 5.89.

Methyl Ethers (VIIIa, IXa, Xa, respectively) of p-Bromotropolone (VIII), o, $o^{\prime}$-Dibromotropolone (IX) and $o, p, o^{\prime}$-Tribromotropolone $(\mathrm{X})$ :-Obtained in the similar manner as above. (VIIIa), pale yellow needles, m. p. $135-136^{\circ}$. Anal. Calcd. for $\mathrm{C}_{8} \mathrm{H}_{7} \mathrm{O}_{2} \mathrm{Br}: \mathrm{C}, 44.68 ; \mathrm{H}$, 3.28. Found: C, 44.01; H, 2.84. (IXa), pale yellow needles, m.p. 132-132.5 . Anal. Caled. for $\mathrm{C}_{8} \mathrm{H}_{6} \mathrm{O}_{2} \mathrm{Br}_{2}: \mathrm{C}, 32.68 ; \mathrm{H}, 2.06$. Found: $\mathrm{C}, 32.72 ; \mathrm{H}, 1.87$. (Xa), pale yellow microneedles, m. p. 110-111 ${ }^{\circ}$. Anal. Caled. for $\mathrm{C}_{s} \mathrm{H}_{5} \mathrm{O}_{2} \mathrm{Br}_{*}: \mathrm{C}, 25.69 ; \mathrm{H}, 1.35$. Found : C, 25.52 ; H, 1.48 .

Bromination of $(\mathrm{Vc}):-$ Brown crystalline precipitate separated on the addition of 1 mole of $\mathrm{Br}_{2}$ to $(\mathrm{Vc})$ in water. After recrystallizations, it was identified as $o, p, o^{\prime}$-tribromotropolone $e^{9}$, by mixed fusion.

The authors wish to acknowledge their indebtedness to Dr. R. Majima for his unfailing encouragement and to Mr. Y. Kitahara for the samples of the bromo derivatives. The authors are also indebted for the donation of Grant in Aid for Scientific Research 
by the Ministry of Education, and to Sanga Kôgyô Co, Ltd., for financial support.

\section{References.}

1) (a) Nozoe: Science of Drugs, 3, 171 (1949). (b) Nozoe, et al. : To be published.

2) Nozoe: The Proceedings, 26 (No. 9) 30 (1950).

3) Dewar: Nature, 155, 141, 479 (1945). Dewar seems to be considering some ionic structures for colchicine. (Cf. Scott, Tarbell: J. Am. Chem. Soc., 72, $240(1950)$. The present authors have not been able to see the original works of Dewar's.)

4) Barltrop and Nicholson: J. Chem. Soc., 1948, 116; Birkinshaw, Chambers, Raistrick: Biochem. J., 3E, 242 (1942).

5) Kurita, Nozoe, and Kubo: J. Chem. Soc. Jap., T1, 534 (1950); Kurita and Kubo: Bull. Chem. Soc. Jap., in press; Hazato, Ikenoue, Maruha, and Kitahara: Presented at the Annual Local Meeting of the Chem. Soc. of Japan in Sendai, July 3, 1950; Maruha, Hazato, Kon, and Nozoe: Ibid., Dec. 4, 1950.

6) Nozoe, Kitahara, Yamane, and Yoshikoshi: The Proceedings, 27 (No. 1) 18 (1951).

7) Katsura, Sato, Akaishi, Nozoe, Seto, and Kitahara: Ibid., 27 (No. 1) 31 (1951).

8) The microanalyses were carried out by Messrs. Hirai and Hayatsu of the Sankyô Co. Ltd.

9) Nozoe, Seto, Kitahara, Kunori, and Nakayama: The Proceedings, 26 (No. 7) 38 (1950). 